\title{
MRIによる子宮腺筋症分類は、腹腔鏡下子宮全摘術の難易度と関連する
}

京都第二赤十字病院産婦人科 ${ }^{1}$ 、東京大学医学部附属病院 女性外科 ${ }^{2)}$ 南川麻里 ${ }^{1,2)}$ 、原田美由紀 ${ }^{2)}$ 、平田哲也 ${ }^{2)}$ 、高村将司 ${ }^{2}$ 、甲賀かをり ${ }^{2)}$ 、 平池 修2)、大須賀穣 ${ }^{2}$ 、藤井知行 ${ }^{2)}$

\section{Subtypes of adenomyosis assessed by MRI is useful to weigh the relative difficulty of laparoscopic hysterectomy.}

\author{
Mari Minagawa ${ }^{1,2)}$, Miyuki Harada ${ }^{2)}$, Tetsuya Hirata ${ }^{2)}$, Masashi Takamura ${ }^{2)}$, Kaori Koga ${ }^{2)}$, \\ Osamu Hiraike $^{2)}$, Yutaka Osuga ${ }^{2)}$ and Tomoyuki Fujii ${ }^{2)}$ \\ Japanese Red Cross Kyoto Daini Hospital, Department of Obstetrics and Gynecology ${ }^{1)}$, \\ The University of Tokyo Hospital, Department of Obstetrics and Gynecology ${ }^{2)}$
}

\begin{abstract}
Objective: To evaluate the relative difficulty of laparoscopic hysterectomy (LH) for adenomyosis by categorizing them into four subtypes.

Methods: We retrospectively collected 56 cases of adenomyosis treated by laparoscopy at our hospital from January 2007 to December 2012. After subcategorizing them into four subtypes on the basis of MRI geography (subtype 1: intrinsic subtype, subtype 2: extrinsic subtype, subtype 3: intramural subtype, subtype 4: indeterminate subtype), we statistically analyzed the surgical results including operation time, blood loss during operation and conversion rate to open surgery using Mann-Whitney U test.

Results: The operation time for subtype 1 adenomyosis was shorter than that for subtype 2 adenomyosis (147 vs. 215 min, $\mathrm{p}<0.005$ ). Compared to subtype $2 / 3$, subtype 1 had small amount of blood loss during operation (260 vs 60/230 ml, respectively, $\mathrm{p}<0.05$ ). Compared to subtype $2 / 3 / 4$, subtype 1 has small proportion of conversion to open surgery $(0$ vs 25/20/ $10.3 \%$, respectively,), which was not statistically significant. We further revealed that revised American Society for Reproductive Medicine (rASRM) score of subtype 2 patients was higher than those of subtype 1/3 patients (60 vs $2 /$ 2 points, respectively, $\mathrm{p}<0.005, \mathrm{p}<0.01)$.

Conclusions: Categorization of adenomyosis based on MRI finding was considered to be an efficient method because of the increased amount of blood loss and elevated rASRM score of subtype 2 adenomyosis. Therefore, subtype 2 was considered to be the most difficult entity of adenomyosis in LH. Although the difficulty of LH for subtype 4 adenomyosis should be further investigated, our analysis implied the importance to categorize adenomyosis by MRI, and this method can be useful for evaluating the difficulty of LH.
\end{abstract}

Key words: adenomyosis, total laparoscopic hysterectomy (LH), MRI, categorize

\section{【緒 言】}

子宮腺筋症のため子宮摘出を余儀なくされる場合、 腹腔鏡下子宮全摘術（laparoscopic hysterectomy, 以下LH）であれば、開腹による子宮全摘術に比 べて、低侵襲であり、入院期間の短縮も可能であ る1)。一方、技量に応じて安全にLHを遂行するに
は、術前にLHの難易度を推測することが重要で ある。LHの完遂率と、BMI、摘出子宮の大きさ、 既往腹部手術歴が関係しているとの報告がある が、子宮腺筋症のMRI所見とLHの難易度につい てはいまだ報告がない2）。今回我々は、子宮腺筋 症に対するLHの手術難易度と、術前の子宮腺筋 症評価に用いたMRI所見との関係を、子宮腺筋症 
のタイプ分類法 ${ }^{3)}$ を用いて検討したため、ここに 報告する。

\section{【方法】}

2007年 1 月から 2012 年 12 月までに当院におい て、過多月経、月経困難症などの理由にて手術適 応があると判断され、LHを含む術式が施行され た子宮腺筋症症例 56 例を後方視的に抽出した。術 式に関しては、症状の改善を目的とし、術中に新 たに子宮内膜症性病変を認めれば、その切除も追 加で施行している。本研究については当院倫理委 員会に諮り、患者には文書にて同意書を取得した。 Kishiらの報告したMRIによる子宮腺筋症分類 ${ }^{3)}$ を用いて、各症例を4つのsubtype (subtype 1: intrinsic subtype, subtype 2: extrinsic subtype, subtype 3: intramural subtype, subtype 4: indeterminate subtype）に分類した（図 1 )。本 分類の際には、 2 名の産婦人科医が画像を見た上 で意見の一致を確認した。術者には、当院にて内 視鏡手術に従事し、なおかつ以前に術者として腹 腔鏡下手術を 100 例以上施行した経験のある、卒 後10年目以上の産婦人科専門医複数名があたっ た。また第一助手には、当院にて内視鏡手術に従 事する日本産科婦人科内視鏡学会腹腔鏡技術認定 医複数名が指導にあたった。すべての症例におい て、術者の選択は、今回の検討に用いたMRIによ る子宮腺筋症分類を考慮せずに行われた。

当院ではLHを以下の通りに定型化している。 上部勒帯を処理したのち、尿管の走行を確認のう え、子宮動脈を単離、凝固切断する。膀胱を剥離 し、傍子宮結合織を凝固切断し、胵パイプを挿入
して腔管を切断し、断端を縫合する。

LHの難易度が高いほど、手術時間、術中出血量、 開腹手術への移行率は高值を示すと仮定した。 LHの難易度に影響する因子として、子宮腺筋症 のsubtype、rASRM (revised American Society for Reproductive Medicine) scoreを検討した。 各症例の、リスク因子、術前症状についてはF検 定を用いて解析した。また、手術時間、術中出血 量、開腹手術への移行率、rASRM scoreについ ては、各 2 群間においてMann-Whitney U検定を 用いて解析した。統計学的softwareは、StatFlex ver. 6.0 software (Artech Co., Ltd, Osaka, Japan）を用いた。またp值0.05以下を有意差があ るものと判定した。

\section{【結 果】}

今回解析した 56 例の年齢は $43.2 \pm 3.2$ 歳、経妊数 は $1.8 \pm 2.0$ 回、経産数は $0.86 \pm 0.94$ 回、BMIは 22.7 $\pm 4.4 \mathrm{~kg} / \mathrm{m}^{2}$ だった(いずれも平均土標準偏差)。 これら56例の子宮腺筋症を術前に撮影したMRIに より 4 グループに分類したが、subtypeの内訳は、 subtype 1（intrinsic subtype）が10例（18\%)、 subtype 2 (extrinsic subtype) が12例 (21\%)、 subtype 3 (intramural subtype) が 5 例 ( $9 \%$ )、 subtype 4 (indeterminate subtype) が28例 (50\%) であった。子宮腺筋症発症のリスク因子であると される、経産数、子宮内膜掻把術、帝王切開、子 宮筋腫核出術などの既往歴に対して検討を行った が、いずれもsubtype間において頻度の有意差を認 めなかった（表1）。術前の症状に関して subtype 間における頻度の検討をしたが、過多月経のあっ

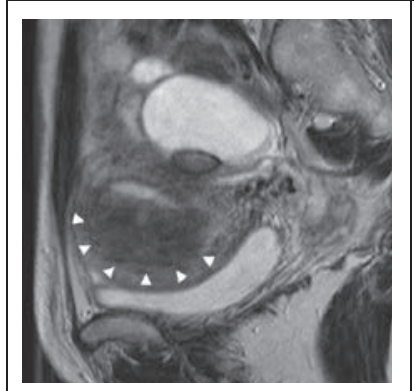

文献 2 より

subtype 1

(intrinsic type)

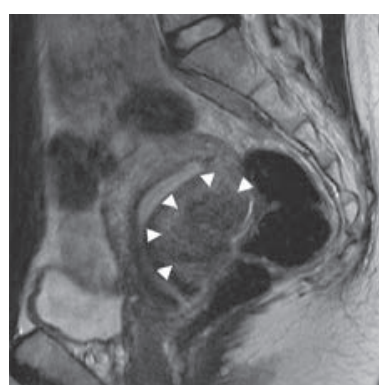

文献 2 より subtype 2

(extrinsic type)

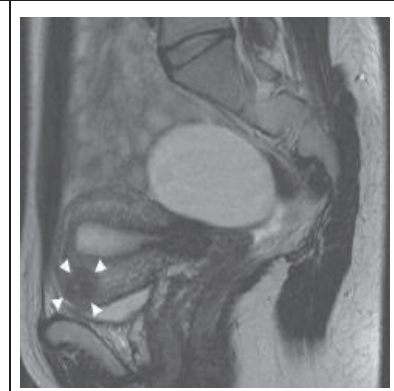

文献 2 より

subtype 3

(intramural type)

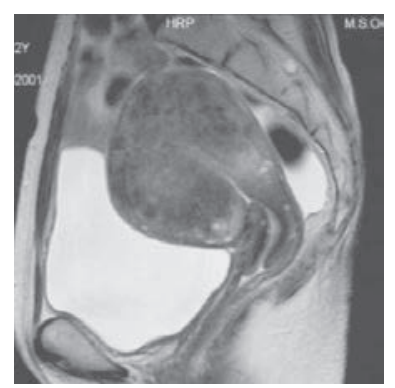

当院症例

subtype 4

(indeterminate type)

図 1 子宮腺筋症のMRI分類（文献2より） 


\begin{tabular}{|c|c|c|c|c|}
\hline & $\begin{array}{l}\text { subtype1: } \\
\text { intrinsic type } \\
(n=10)\end{array}$ & $\begin{array}{l}\text { subtype } 2 \text { : } \\
\text { extrinsic type } \\
(n=12)\end{array}$ & $\begin{array}{l}\text { subtype } 3: \\
\text { intramural type } \\
(n=5)\end{array}$ & $\begin{array}{l}\text { subtype } 4: \\
\text { indeterminate type } \\
(n=28)\end{array}$ \\
\hline 経産数 & $1.0 \pm 0.8$ & $0.8 \pm 0.9$ & 1. $0 \pm 1.2$ & $0.8 \pm 1.0$ \\
\hline 子宮内膜掻爬術の既往 & $0 / 10 \quad(0 \%)$ & $1 / 12(8 \%)$ & $1 / 5 \quad(20 \%)$ & $7 / 28 \quad(25 \%)$ \\
\hline $\begin{array}{l}\text { 帝王切開ないし } \\
\text { 子宮筋腫核出術の既往 }\end{array}$ & $0 / 10 \quad(0 \%)$ & $1 / 12(8 \%)$ & $1 / 5 \quad(20 \%)$ & $1 / 28(4 \%)$ \\
\hline 過多月経あり & $7 / 10 \quad(70 \%)$ & $7 / 12(58 \%)$ & $4 / 5 \quad(80 \%)$ & $20 / 29 \quad(69 \%)$ \\
\hline 月経困難症あり & $10 / 10(100 \%)$ & $10 / 12(83 \%)$ & $5 / 5 \quad(100 \%)$ & $28 / 29 \quad(97 \%)$ \\
\hline
\end{tabular}

いずれも群間に有意差なし

た症例は、 subtype 1: 7/10例（70\%)、 subtype 2: $7 / 12$ 例 $(58 \%)$ 、 subtype 3: 4/5 例 $(80 \%)$ 、 subtype 4: 20/29例（69\%）であり、月経困難症 のあった症例は、subtype 1: 10/10例 (100\%)、 subtype 2: 10/12 例 (83\%)、 subtype 3: 5/5 例 (100\%)、subtype 4: 28/29例（97\%）であり、共 に有意差を認めなかった。

手術時間の中央値は、subtype 1: 147 (95\% CI: 104-172) 分、subtype 2: 215 (95\% CI: 120-323) 分、 subtype 3: 159 (95\% CI: 122-245) 分、 subtype 4: 174 (95\% CI: 75-338）分であり、subtype 2で はsubtype 1 に比べて手術時間が有意に長かった (図 2)。術中出血量の中央值は、subtype 1: 60 (95\% CI: 0-220) ml、 subtype 2: 260 (95\% CI: 100-1740) ml、subtype 3: 230 (95\% CI: 90-290) ml、subtype 4: 90 (95\% CI: 0-2275) mlであり、 subtype 1ではsubtype 2/3に比べて出血量が有意 に少なく、subtype 2ではsubtype 4に比べて出血
量が有意に多かった（図 3 ）。術中出血量が1000 mlを超えた症例は、subtype 2で1/12例、subtype 4 で $2 / 29$ 例であり、輸血を必要とした。いずれの 症例にも deep infiltrating endometriosisがあり、 病巣切除の際に大量出血をきたしたものと考えら れた。うち、subtype4での 1 例については、尿 管と子宮動脈の同定が困難であったため、開腹移 行しており、2500 $\mathrm{ml}$ という本検討において最多 量の出血をきたした。 LHを予定した56症例中、 LHを完遂できたのは49例（87.5\%）であり、 subtype 1では開腹手術への移行率は $0 \%$ すなわ ち全例LHを完遂できたのに対し、subtype 2/3/ 4 では25/20/10.3\%の開腹手術への移行を認めた が、subtype 1 vs. subtype 2/3/4においてそれ ぞれ $\mathrm{p}=0.0889 、 \mathrm{p}=0.1432, \mathrm{p}=0.2898$ であり、統計 的有意差はなかった。開腹移行に至った例として、 ダグラス窩の完全閉鎖による子宮後面と直腸との 剥離が困難だった症例や、広間膜の癒着により子

手術時間（分）

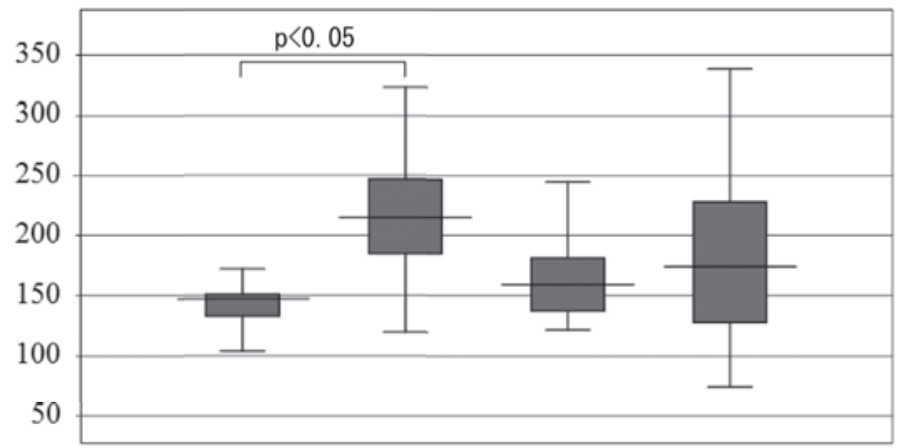

subtype1 subtype2 subtype3 subtype 4 


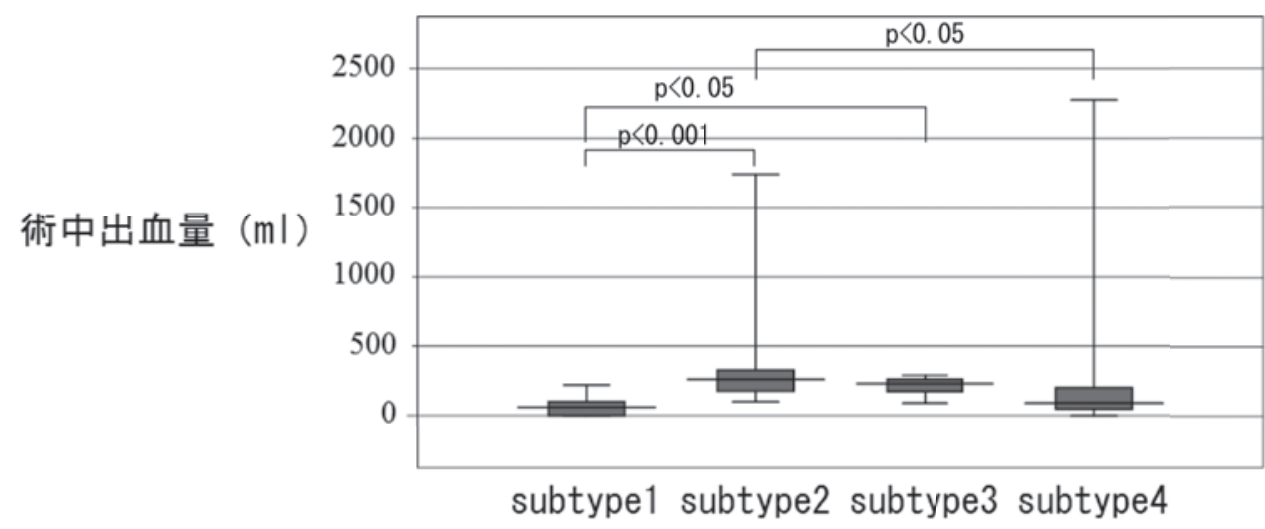

図3 術中出血量と子宮腺筋症分類

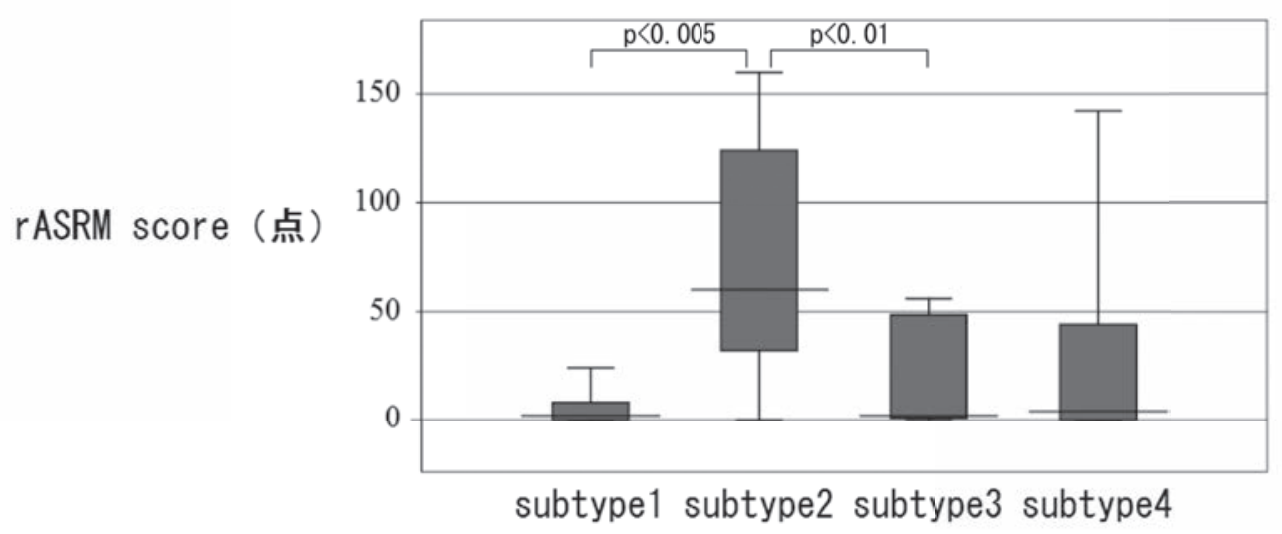

図4 rASRM scoreと子宮腺筋症分類

宮動脈や尿管の同定が不可能であり定型化された 手技が困難だった症例が挙げられた。術中に評価 したrASRM scoreの中央值は、subtype 1: 2 (95\% CI: 0-24）点、 subtype 2: 60 (95\% CI: 0-160）点、 subtype 3: 2 (95\% CI: 0-56) 点, subtype 4: 4 (95\% CI: 0-142) 点であり、 subtype 2ではsubtype 1/3 に比べてr-ASRM scoreが有意に高かった（図 4)。

\section{【考察】}

子宮腺筋症は、30-50歳代の女性の $20 \%$ に発生 する子宮の良性腫瘍である ${ }^{4)}$ 。月経困難症が軽度 の場合や閉経年齢に近い症例には、NSAIDsによ る対症療法やGnRHアゴニストなどによる閉経逃 げ込み療法が選択されることも多いが、月経困難 症が重症である症例、過多月経による貧血をきた す症例には外科的治療が適応となる。妊孕性の温 存希望がない場合には、子宮を摘出することが根 本的な治療である。LHは、開腹による子宮摘出 に比べて手術侵襲が少なく、整容性に優れ、術中 出血量が少なく、入院期間の短縮が可能であるこ とがメリットであるが ${ }^{4)}$ 、腹腔鏡下手術は、開腹 手術に比べて術者の技量に大きく影響を受けやす
いため、術者と症例との適切なマッチングが安全 な手術遂行に必要不可欠である。しかし、子宮腺 筋症のLHに対する手術難易度の予測に関しては 既報がない。

一方、子宮腺筋症について、2012年にKishiら が新たな 4 分類を提唱している。MRI上、子宮腺 筋症病巣が子宮のどの位置に局在するかによって subtypeを設定したもので、subtype 1 (intrinsic type）は子宮内膜に接するが漿膜側には達しない 子宮腺筋症、subtype 2 は宮漿膜側に接するが 子宮内膜に接しない子宮腺筋症、subtype 3 は周 囲を正常子宮筋層に取り囲まれた局所的な子宮腺 筋症、subtype 4は上記いずれにも分類できない 子宮腺筋症であると定義した上で、Kishiらは subtypeによって子宮腺筋症の発生起源が異なる 可能性を示唆している。我々は、この分類方法に 注目し、当院手術症例を統計的に解析した。その 結果、術中出血量、手術時間、開腹移行率の程度 から考えると、LHの施行はsubtype 2で困難で、 subtype 1で容易といえた。

subtype 2でLH難易度が高かった理由は、子宮 内膜症の重症度の指標であるrASRM scoreが、 
subtype $1 / 3 / 4$ の2/2/4点に対してsubtype 2で は60点と有意に高く、術中癒着が高度であるため と考えられた。また、このことは、異所性内膜が 子宮漿膜から侵入することが子宮腺筋症の発生機 構のひとつであるという仮説を支持する ${ }^{5)}$ 。そう であれば、現在は子宮腺筋症と診断されている病 変のうち、subtype 2はむしろ deep infiltrating endometriosisのひとつの表現型と捉えることも 妥当であるかもしれない( ${ }^{6,7)}$ 。

subtype 1でLH難易度が低かった理由として は、rASRM scoreが低く、術中癒着が軽度であ るためと考えられた。Kishiらは、異所性内膜の 子宮筋層への侵入が、物理的な傷害を起点として 生じうるため、subtype 1ではその他のsubtype に比べて経産婦・子宮内膜掻把術の既往が多かっ たと報告しているが涂、本村では有意差を認め なかった。子宮筋腫核出術・帝王切開術の既往に 関しても、subtype 2 とその他のsubtypeに有意 差を認めなかった。しかし、本検討は手術療法が 施行された子宮腺筋症症例のみを抽出している点 で、上記の仮説を検討するには不適当である。手 術に至らなかった症例も含め、MRIで診断した子 宮腺筋症症例をMRIによる子宮腺筋症分類によっ て分類し、改めて検討を行う必要があるだろう。

subtype 3 では症例数が 5 例と少なく有意な解 析ではないが、出血量・手術時間のいずれに関し ても subtype 1に近い分布を示した。筋層内に局 所性に発達する子宮腺筋症の発生起源は子宮筋層 内のミュラー管遺残組織の化生であるとする説が 報告されており ${ }^{8)}$ 、腹腔内癒着の可能性は少ない ことが推測されるため、十分な症例数が得られた ならば難易度としてはsubtype 1に近い、容易な ものに分類できることが推測される。なお、 subtype 3 で唯一開腹移行した 1 例は、子宮筋腫 核出術既往により高度の術後癒着があった。

Subtype 4は他のsubtypeに分類不能な症例の 集合であり、子宮腺筋症病変が進行するにつれて どのsubtypeもやがて subtype 4に分類されうる 可能性がある。そのため、中には今回の検討で LHの難易度が高いと考えられたsubtype 2の進行 例も含まれ、手術手技的には容易でない可能性が 十分考えられるため、今後も更なる症例の蓄積を 要する。そのため、この分類だけですべての子宮 腺筋症のLHの手術難易度を予測できるわけでは ないが、本研究でも示されたようにsubtype 4以 外のsubtype と診断できるものに関しては、LHの 手術難易度を予測するのにある程度有用であると
考えられる。

今回の検討では、複数の術者による執刀である ことから、それぞれの術者の技量が結果へ影響を 与えた可能性を考慮したが、当院ではLH執刀に 方法に記載したような制限を課しており、術者の 技量水準はある一定以上で保たれており、統計的 検討を行うに足ると考えた。また、今回の検討では、 病変が認められれば、 deep infiltrating enometriosis の病巣の切除や、卵巣子宮内膜症性囊胞の摘出も 施行している点で、純粋なLHの難易度とは言い 切れない。しかし、本検討の症例においては月経 困難症など症状の改善を目的として手術を行って おり、術中に認めた病巣があれば症状改善のため 術式を追加することは必要であり、文字通りの LHだけを施行して終了するのでは不十分である。 むしろ純粋にLHのみを施行した症例に限っての 検討では、症状改善のためのLH、すなわち子宮 の摘出と病巣の切除を予定した手術、の難易度を 術前に推測したいという本検討の目的には不適当 であると考え、LHを含む術式を施行した子宮腺 筋症全症例での検討を行った。

今回の検討結果から、LHの経験症例がそしい 術者にはsubtype 1もしくはsubtype 3の子宮腺筋 症症例を、LHの手技に十分習熟していると考え られる術者にはsubtype 2 もくはsubtype 4の子 宮腺筋症症例を執刀させることが、LHの安全な 遂行に重要ではないかと考えられた。

\section{【結 語】}

当院症例の解析では、子宮腺筋症のsubtype1 でLHの手術難易度が低く、subtype 2で高いと言 えた。症例数が限られていることから今後も更な る検討を要するが、MRIによる子宮腺筋症分類は、 子宮腺筋症に対しLHを行う際、その難易度をあ る程度予測できる点で有用であることが示唆され た。

なお、本論文の要旨は第53回日本産科婦人科内 視鏡学会において発表した。

\section{参考文献}

1 ) Wright KN, et al. : Costs and outcomes of abdominal, vaginal, laparoscopic and robotic hysterectomies. Journal of the Society of Laparoendoscopic Surgeons 2012 ; 16: 519-524.

2 ) Leonard F, et al. : Total laparoscopic hysterectomy: 
preoperative risk factors for conversion to laparotomy. Journal of Minimum Invasive Gynecology 2005 ; 12: 312-317

3 ) Kishi Y, et al. : Four subtypes of adenomyosis assessed by magnetic resonance imaging and their specification. American journal of Obstetrics and Gynecology. 2012 : 114.e1-114.e7.

4 ) Prino A, et al. : Total laparoscopic hysterectomy versus total abdominal hysterectomy: an assessment of the learning curve in a prospective randomized study. Human Reproduction. 1999; 14: 2996-2999.

5 ) McElin TW, Bird CC : Adenomyosis of the uterus. Obstet Gynecol Annu. 1974 ; 3: 425-441.

6 ) Chapron C, et al. : Deep infiltrating endometriosis: relation beween severity of dysmenorrhea and extent of disease. Human Reproduction 2003 ; 18: 760-766.

7 ) Larsen SB, et al. : Adenomyosis and junctional zone changes in patients with endometriosis. Eur J Obstet Gynecol Reprod Biol 2011 ; 157: 206-211.

8 ) Bergeron C, Amant F, Ferenczy A : Pathology and physiopathology of adenomyosis. Best Practice \& Research Clinical Obstetrics and Gynaecology 2006 ; 20: 511-521. 